\title{
A collaborative platform for science teaching at elementary and middle school level
}

\author{
Adelina Sporea $^{1}$, Dan Sporea ${ }^{1}$, Vasile Păiş ${ }^{2}$ \\ ${ }^{1}$ National Institute for Laser, Plasma and Radiation Physics, Center for Science Education and Training, Măgurele, Romania \\ ${ }^{2}$ Computerpower SRL, Bucharest, Romania
}

Email address:

adelina.sporea@inflpr.ro (A. Sporea),dan.sporea@inflpr.ro (D. Sporea), pvf2005@gmail.com (V. Păiş)

To cite this article:

Adelina Sporea, Dan Sporea, Vasile Păiş. A Collaborative Platform for Science Teaching at Elementary and Middle School Level. International Journal of Elementary Education. Vol. 4, No. 1, 2015, pp. 1-7. doi: 10.11648/j.ijeedu.20150401.11

\begin{abstract}
This paper presents the collaborative platform we developed in the frame of the national educational project "Inquiry-Based Education in Science and Technology (i-BEST)" to support science teaching and learning from kindergarten to middle school. Two of inquiry-based science activities are described, activities designed to develop children observation, measuring and reporting skills in science classes. Technological aspects of the educational process are supported as school students are taught to build their own measuring instruments, learning in this way their operating principles.
\end{abstract}

Keywords: Community of Practice, Collaborative Platform, Inquiry-Based Teaching, Science Education

\section{Introduction}

Collaborative and cooperative learning refer to a method used to achieve an educational goal as learners work together for the fulfillment of a given task [1,2]. Collaborative learning was proved to assist students to reach better achievements, to develop more effective psychological and social connections, to improve social behavior, to increase their self-esteem, and to achieve autonomous problem-solving skills [3-7]. Through collaborative learning students are trained to work in group in a cooperative manner rather than in a competitive way, to construct knowledge rather than memorize information, to participate to decision making, to select the appropriate means to solve a problem, to have an increased control over the learning process, as this approach is student-centered [8]. Both individual and social processes have to be considered in analyzing the motivation during collaborative learning activities [9]. ICT is seen as an opportunity to promote and support collaborative learning, virtual environments being both a tool and a medium for educational activities [10-12]. Those involved into the development of computer supported collaborative learning (CSCL) tools have to be aware of the pedagogical, technical, and organizational challenges they have to face [13]. Other obstacles in achieving expected results through collaborative learning could be gender, ethnicity, and cultural orientation [14].

Efforts were made in the last years at European level to revolutionize the methods science and mathematics are taught at pre-university level, the inquiry-based science education (IBSE) becoming the key word of the educational process [15].

Computer-based learning environments were designed to support "discovery learning" [16], or inquiry-based learning $[17,18]$, when students working in a constructivist manner participate to their own knowledge development.

The i-BEST project (Inquiry-Based Education in Science and Technology, http://education.inflpr.ro/ro/IBEST.htm) has as major focus the science teaching by inquiry-based learning In the frame of this project we propose to schools (from kindergarten to middle school) different activities supported by appropriate learning units and training kits, in the field of science of measuring, optics, acoustics, electricity. Some of the learning units are original and some are translations from European or American projects. These learning units are part of the e-learning platform we developed, the TeachScience platform, which includes also a virtual library (http://81.181.130.13/teachscience/). School activities related to science learning are supported by a collaborative platform, aiming to create a nationwide community of practice (http://81.181.130.13/ibest/). As compared to the "classical" approach on collaborative learning, when students organized in small groups are solving a problem, in our implementation we are trying to channel the efforts of different schools, with various development and achievement levels, and spread across the country, towards the inquiry on a common science subject. 
The present paper refers to two of the inquiry-based science activities we run in the context of this collaborative platform. The two activities were designed to be accessible to school students of five to 14 years old. School teachers have the possibility to select the appropriate investigations they think to be more appropriate to their students.

\section{The Collaborative Platform and Related Activities}

\subsection{Platform Description and Functions}

For each inquiry-based science activity, specific instructions are given to teachers on the collaborative platform, concerning: (i) how to register; (ii) the procedure to be followed for the activity development; (iii) the way the results have to be reported. Each of the platform's modules was implemented using the PHP general-purpose programming language. One of the challenges was to keep the modules separated, by having different users and different data sets, but still have a common set of functions that can be re-used between modules. This goal was achieved by keeping separate data sets for each of the modules and creating a common library of functions available to all modules. This separation was performed physically, on the hard disk.

The main reason for choosing this implementation pattern was due to the fact that each teacher is free to choose which modules he considers to be of interest for his class. Therefore, he/ she must be able to individually access the platform's modules. Furthermore, in different years the teacher may access the platform with different classes. In this case, even though he/ she may use the same credentials, still he/she must register again in order to declare his interest in participating in the activity. This also helps the platform to keep accurate participation reports, since a teacher can not access a module by accident, instead access must be requested and approved, thus denoting a genuine interest in the activity.

On a technical side, by keeping separate data for each activity, the platform benefits from increased data access speed. Each data set contains only relevant information for the activity being implemented and thus indexes are particularly optimized, making the complexity of selecting useful information to be $\mathrm{O}(1)$.

Implementation of the module "Spring is coming" was realized based on the site overall structure, described above. Thus, it is a dedicated module for this activity, backed by a dedicated database, storing the relevant information. Similar to every other module, it contains two areas: a public zone, accessible by everyone publicly over the Internet, and an internal zone, accessible only to registered users, after their account has been approved.

The public zone gives enough information for a teacher to make a decision about participating in the activity. If he considers the activity to be interesting enough, he/ she must announce his/ her intention to participate by completing the "Registration" form. Afterwards, his/ her account will be activated and the teacher will gain access to the private zone, where he/she can upload activity reports for his/ her class.

The following sections are available in the public zone:

- "Home": general information about the module;

- "How you can participate": information regarding the participation to the activity;

- "Information about species": description of different plants monitored through the activity;

- "Participants Distribution": a map indicating the active participants from each county;

- "Registration": allows for a teacher to register for the activity;

- "Final Reports": a section dedicated to the final reports made available as a result for the current activity;

- Archives of past activities, with their corresponding final reports.

The internal area of the module, available only after account approval, contains a set of pages allowing the teacher to upload data recorded by his/ her class. For this purpose, he/ she can download templates for intermediary and final reports. Afterwards, he/ she must upload the completed documents in the platform.

In order to make it easier to work with the reports, the platform accepts multiple file formats. These include $d o c$, $d o c x$ and $p d f$ for the intermediary reports and jpg,jpeg for the final reports. In the case of the final reports, the uploaded images are kept in the original format, but thumbnails are automatically generated by the system in order to increase the performance of the "Final Reports" page, where smaller versions of the images are needed.

Collaboration amongst participants was made possible by integrating a "forum" software in the platform. For this purpose, several of the existing applications were analyzed and finally it was decided upon "phpBB" [19]. The main reasons for choosing this particular application were its implementation in PHP, the same language as the platform's, and the ability to easily integrate it inside the module, by configuring it to use the authenticated users.

Besides the aforementioned areas, there is a separate section available to the site administrator, from which accounts can be approved and reports can be checked.

Similar to the previous module, the activity "Weather" has the same basic features: a public area, with general information about the activity, and a restricted area, offering the participants the possibility to upload their measurements.

The following sections are available in the public zone:

- "Home": general information about the module;

- "How you can participate": information regarding the participation to the activity;

- "Temperature monitoring": specific information related to temperature measurements;

- "Precipitations level monitoring": specific information related to monitoring the precipitations;

- "Wind speed monitoring": specific information related to monitoring the wind speed;

- "Participants Distribution": offers an interactive map with the geographical distribution of the participants;

- "Registration": allows for a teacher to register for the 
activity.

After having his/ her account approved, the teacher can upload the measurements of the class in the corresponding sections available from the private zone of the module. Data is then stored in a specific format which allows querying for both the actual data and derived statistical information.

Available statistical data include averages for geographical areas and country wide. These results can be accessed from the interactive map available in the "Participants Distribution" section. Thus a teacher can compare the measurements of his/ her class with the averages for the area his/ her school is located in.

In order to implement the interactive map, a JavaScript library named "Raphael" [20] was used. It allows drawing an interactive map from a vectorial format. When selecting a certain region and a certain participant, the charts being shown were realized using the "HighCharts" [21] library.

Data provided by the participants are used only for research and results reporting, the National Institute for Laser, Plasma and radiation Physics being registered to the National Supervisory Authority for Personal Data Processing under No. 15407. By registering on the collaborative platform, the participants agreed on the use of their activity uploaded outcomes for research and reporting purposes.

\subsection{Description of the "Spring is Coming" Activity}

Based on the collaborative platform, several inquiry-based activities are defined covering topics such as: nature observation during the spring time; weather monitoring; noise pollution; water quality; risk associated to UV radiation. In each activity, an investigation to be run over a time interval ranging between 4 and 8 weeks are proposed to preschool, primary and middle school teachers.

"Spring is coming" activity was inspired by the Greenwave project we run as partners in the EU's FP7 "Fibonacci" project [22] (http://81.181.130.13/ibest/ module/semnele_primaverii /index.php). In this case, classes are asked to monitor the development of specific plants species starting from early February to late May, and to report weekly the evolution of the plants they observed. On the project site, participants are acquainted with the nine recommended plant species. For each such plant, school children learn about the geographic distribution, its appearance and dimensions, as well as few data on the practical use of the respective plant. In some situations, recommendations concerning the observation process and on data handling are given, for participants convenience. For an easy identification of the plant some photos are provided on the web site. The side includes also the map of Romania with updates on the participants' distribution by counties (http://81.181.130.13/ibest/module/semnele_ primaverii_2013/harta.php). In developing the activity, students have to fill in specific worksheets for an organized work and for their instruction on how to follow a research procedure.

By the end of the project life, all participating classes have to upload on the platform a jpg. file of a poster representing the obtained results. The poster has to contain information on: the participating class; school and teacher; references used; data collected; results and conclusions of the study. All these posters are on display (http://81.181.130.13/ibest/module/ semnele_primaverii_2013/index.php?action=rapoarte_finale), so, participants across the country can evaluate their peers, and compare the results.

\subsection{Description of the "Weather" Activity}

The "Weather" activity focuses on the measurements of the meteorological parameters: temperature, wind speed, rain fall. The observations have to be done over two calendar months, daily, with the reporting of the mean value by each weekend. The measured parameters are periodically uploaded in the project data base in order to build an archive of the information provided by all participants.

For each parameter to be monitored detailed instructions are given on the web site (http://81.181.130.13/ibest/module/ vremea/index.php). Besides that, school students are taught to build their own measuring devices, using materials available in the household: a thermometer (http://81.181.130.13/ibest/ module/vremea/monitorizare_temperatura.php), pluviometer (http://81.181-130.13/ibest/ module/vremea/ monitorizare_precipitatii.php), and an anemometer (http://81.181.130.13/ibest/module/vremea/monitorizare_van t.php). In this way, the inquiry process is completed by design and technology training. As compared to the Greenwave project, in this case, when the map is accessed and the mouse points to a county, the list of participating school are displayed (Fig.1) and the visitor can access the data recorded by that school, over the whole investigation period.

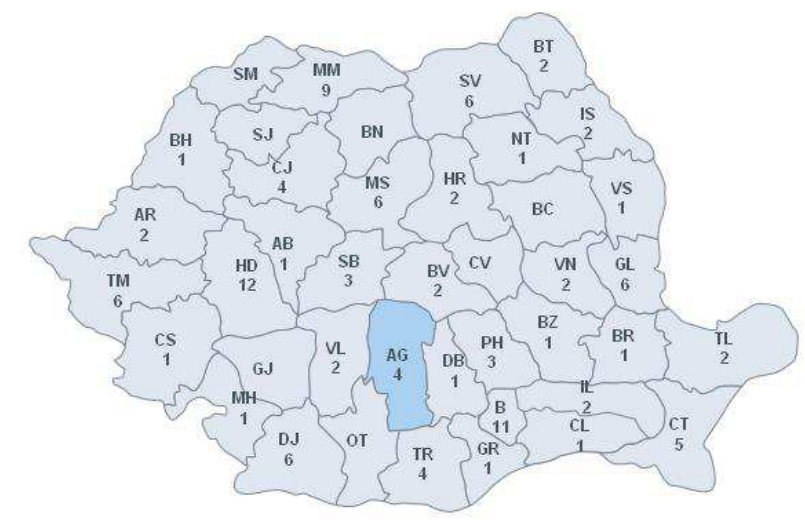

Scoala Gimnaziala (Pitesti, Str. Paltinului, Nr 2)

Scoala Gimmaziala (Pitesti, Str. Paltinului, Nr

Scoala Gimnaziala Oprea lorgulescu (Campulung, Str. Gen. Posoiu, nr. 1)

scoala Gimnazială ,.Mircea Eliade”" (Pitesti, Bd. Petrochimiștilor, Nr.31)

Figure 1. Example of the geographical distribution of participating schools to the "Weather" project.

\subsection{Results}

Fig.2 illustrates two examples of worksheets either written by hand and containing drawings, or by computer with inserted photos from the "Spring is coming" activity. In the case of one middle school, the enthusiasm of the participants was so high that they kept an illustrated diary, where plants and even tree branches were given personal names. The final 
reports are represented by posters (Fig.3).

Examples of graphical representation of the measured data uploaded by school students on weather parameters (temperature, rain and wind seed) are given in Fig. 4, as measured values, mean values in the country and mean

Fisa de observatii

Numele specleI studiate: ZAMBILA

LOcatla in care sa reallzat STUdUU: PARCUL SCOLII

Numete elevilor care au participat la activitatea de investigare si c chsa:

BUDIU LUANA, HOZA MädĂLINA, CATANA ANDEEA, VEDINAŞ ŞTEFANIA, PAŞCA DALIA, CLASA A-IV-A A

ŞCOALA GIMNAZIALÄ SANTTANA / ARAD

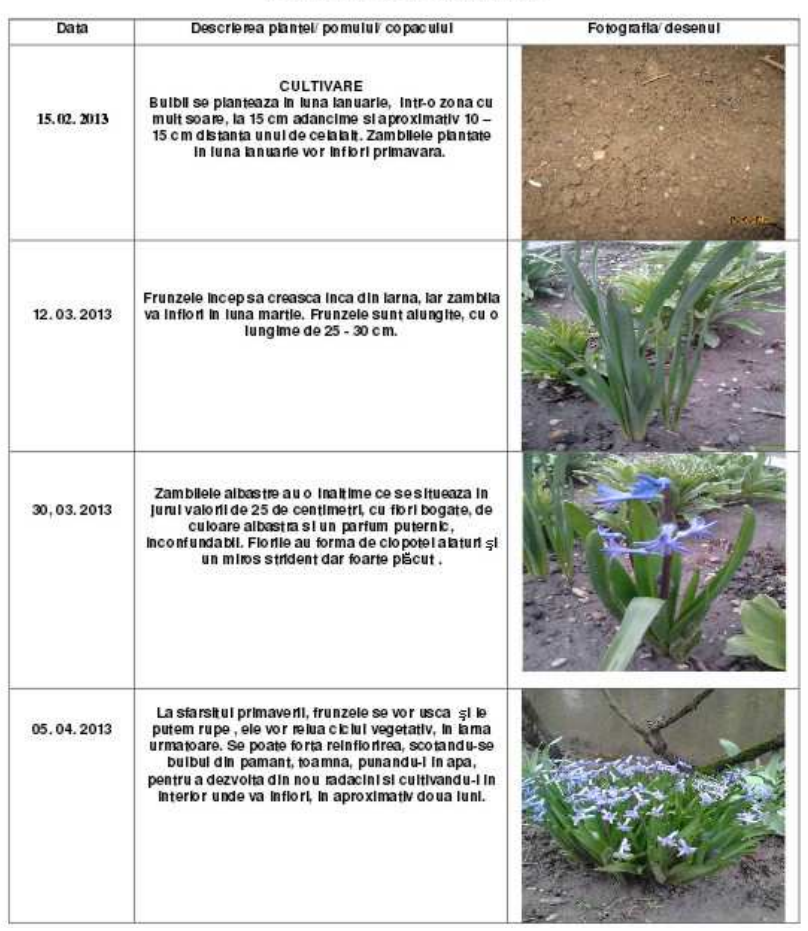

values at country level.

Monitoring is an important aspect of any online platform. This allows us to understand how and when people are accessing the modules and what requirements are imposed on the server. For this purpose, the "AWSTATS" [23] tool is used.

Figure 2. Worksheets completed by students showing their project activities.

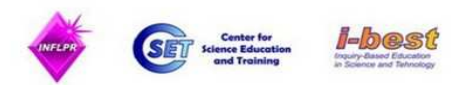

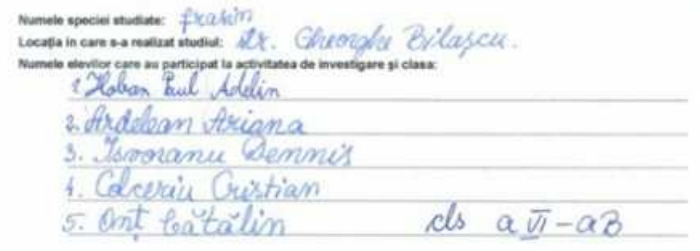

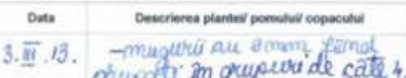

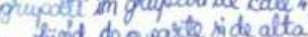

Iaftämon fürd de parte pide aita. pri te a ondution total - cularea este verde-margri

8. II. 13. - mugurii ar tommin. ctemgutei muguvii au oneoplet suptaimara ba sape deschis la culoare. find maro-rescat, in wart asond culoaria mako

15.03.13 - muqutid au 1,4 cm

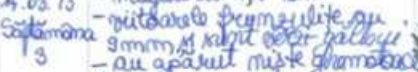
de cublare roscat-matonie, ajond im rowa miste loslife ghemotoacele punt rntafrumate

15. I. 13 - mugutia all $5 \mathrm{~mm}$. Sn trmana- Aunt positionati dim be 3.
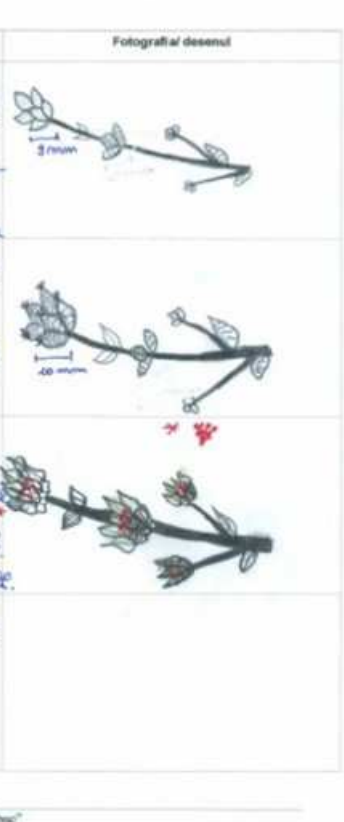

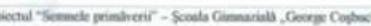


Fig. 5 presents the usage patterns of the platform in 2013, considering the following metrics: unique visitors, number of visits, pages, hits and bandwidth. From the usage representation, it can easily be seen that most of the accesses occur during the school year, while the gaps in the graphic correspond to the vacations.

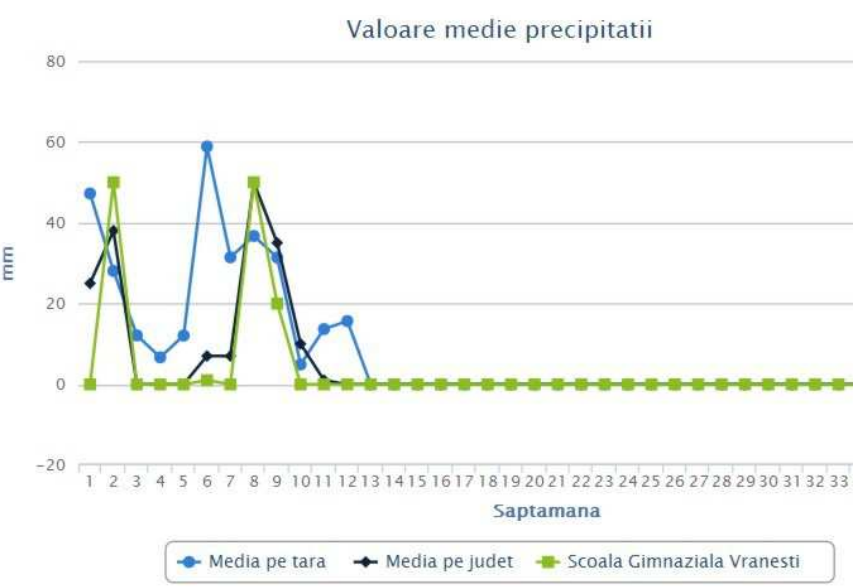

(a)

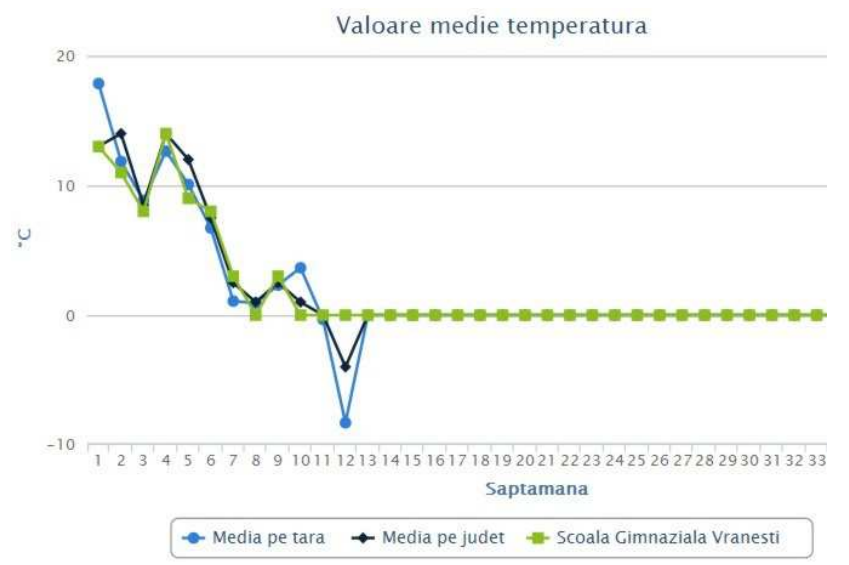

(b)

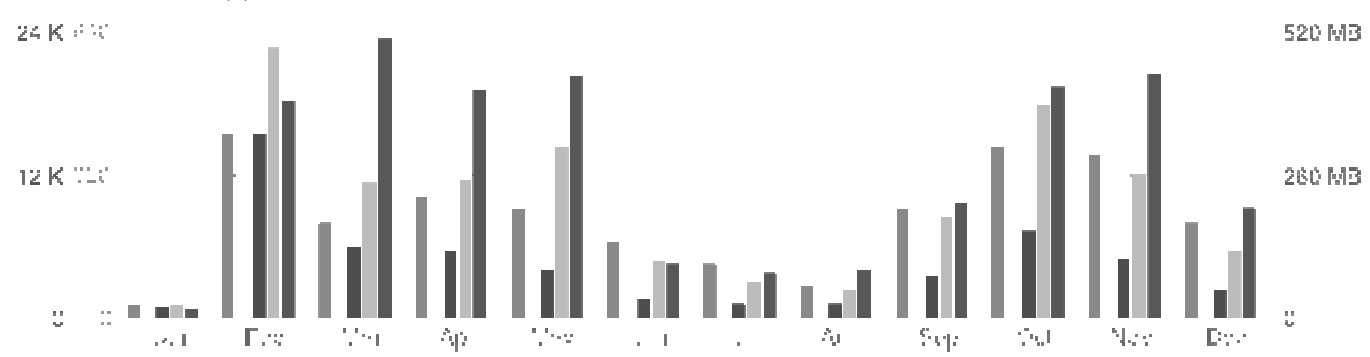

Figure 5. Platform usage in 2013.

Figure 6. Web browser distribution

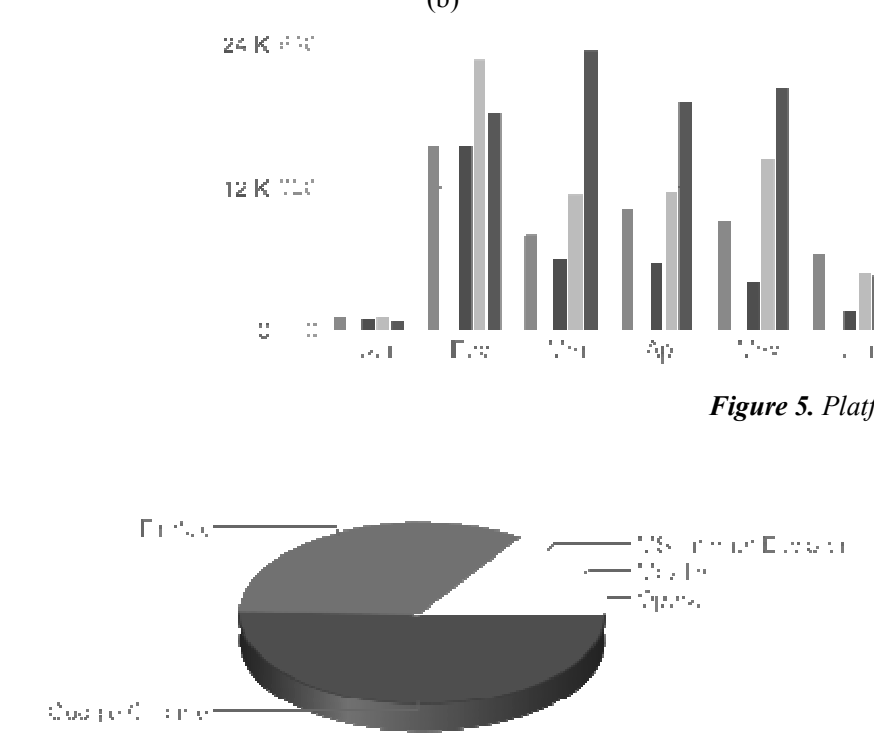

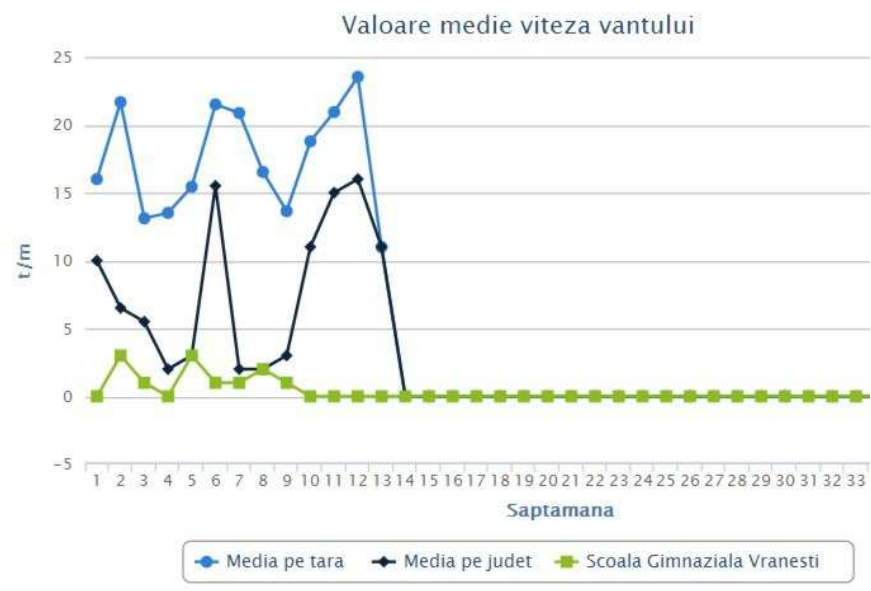

(c)

Figure 4. Examples of the mean rain fall (a), temperature (b), and rain fall (c).

This denotes a genuine interest in the platform and confirms the fact that teachers actually get their classes involved in the activities. Furthermore, by analyzing the first month of 2014 compared with the overall usage in 2013, we noticed an increased interest for the platform.

Another interesting statistic is the distribution of web browsers used by users, shown in Fig. 6 .

The web browser distribution is extracted from the usage recorded in May 2014, which is the month with the highest number of accesses so far. Therefore, it is considered to be representative for the current users of the platform.

It can be seen that modern web browsers, such as Google Chrome and Firefox constitute the large majority of browsers used. Thus, the development of new features will target especially these browsers. Nevertheless, the platform still tries to work independent of browser and operating system used, as long as a sufficiently recent one is used.
The size of data files stored in the platform, including partial reports, final reports and data is presented in Table 1.

Table 1. Storage requirements for different modules

\begin{tabular}{ll}
\hline ..Module & Data Size \\
\hline "Spring is coming" project 2013 & $1,2 \mathrm{~Gb}$ \\
"Spring is coming" project 2014 & $500 \mathrm{Mb}$ \\
"Weather" project 2013 & $522 \mathrm{Mb}$ \\
"Weather" project 2014 & $310 \mathrm{Mb}$ \\
\hline
\end{tabular}


As depicted in Table 1, each module has different requirements in terms of storage. Even more, as teachers use the platform, they start creating more optimized and good looking images and documents, which has the side effect of reducing the storage requirements. On the other hand, current activities, even though are advanced, have not yet completed at the time of this writing.

\section{Conclusions and Future Work}

The paper summarizes our endeavor to develop a national community of practice in relation to science teaching at pre-school, primary and middle school level, using the inquiry-based approach. A collaborative platform was setup serving until now two activities: the "Spring is coming" and "Weather". School students and teachers have the opportunity to run some observations of the surrounding world and to perform some measurements, and to save their weekly results in the platform data base. By the end of the "Spring is coming" activity, participants upload a poster reporting their results, poster visible to the general public. During the "Weather" activity, participating classes recorded and saved weekly on the collaborative platform the measurements they have made during several months regarding the outside temperature, fallen rain quantity and the speed of the wind. All data are available on line, and so, a nation wide distributed mini institute of meteorology was built. The collaborative platform we developed contributed to the setup of a national network of schools, covering the age span from 5 years old to 15 years old, schools working on the same subject, using the inquiry-based learning method. In this way, through the platform they can exchange ideas and best practice, and can compare their methods and results. This approach encourages cooperation and the exchange of ideas among students and teachers.

Another educational dimension of the project refers to the technological challenges it poses to school students as they are required to create their own measuring instruments.

In the next step the platform activities will support the development of some civic responsibilities, school students being encouraged to observe and monitor noise pollution and the quality of water in their environment.

\section{Acknowledgments}

The authors acknowledge the financial support received from the grant 223/ 2012 of the Romanian Executive Agency for Higher Education, Research, Development and Innovation Funding (UEFISCDI), project "Inquiry-Based Education in Science and Technology: i-BEST".

\section{References}

[1] R. Kay and L. E. Dyson, "Learning to collaborate and collaborating to learn: An experiential approach to teaching collaborative systems," JTAER, vol. 1, issue 2, pp. $36-44$, August 2006.
[2] M. Dooly, "Constructing knowledge together," in Telecollaborative Language Learning. A guidebook to moderating intercultural collaboration online, M. Dooly, Ed., Bern, Peter Lang, 2008, pp. 21-45.

[3] H. An, S. Kim, and B. Kim, "Teacher perspectives on online collaborative learning: factors perceived as facilitating and impeding successful online group work, "Contemporary Issues in Technology and Teacher education, vol. 8, issue 1, pp. 65-83, 2008.

[4] D. W. Johnson and R. T. Johnson, “An educational psychology success story: Social interdependence theory and cooperative learning," Educational Researcher, vol. 38, pp. 365-379, 2009.

[5] M.W. Goodwin, "Cooperative learning and social skills: What skills to teach and how to teach them," Cooperative, Intervention in School and Clinic, vol. 35, pp. 29-33, 1999.

[6] D.F. Shell, J. Husman, J.E. Turner, D.M. Cliffel, I. Nath, and N. Sweany, "The impact of computer supported collaborative learning communities on high school students' knowledge building, strategic learning, and perceptions of the classroom," J. Educational Computing Research, vol. 33, No. 3, pp. 327-349, 2005.

[7] G. Lazakidou, and S. Retalis, "Using computer supported collaborative learning strategies for helping students acquire self-regulated problem-solving skills in mathematics," Computers \& Education, vol. 54, No. 1, pp. 3-13, 2010.

[8] K. O. Kane and J. Harms, "Getting started: A guide to collaboration in the classroom", accessed at: http://www.cte. hawaii.edu/publications/Collab_web.pdf.

[9] S. Järvelä, S. Volet, and H. Järvenoja. "Research on motivation in collaborative learning: Moving beyond the cognitive-situative divide and combining individual and social processes." Educational psychologist, vol. 45. No.1, pp. 15-27, 2010.

[10] T. Valtonen, "An insight into collaborative learning with ICT: Teachers' and students' perspectives", Dissertations in Education, Humanities, and Theology, University of Eastern Finland, Joensuu, 2011, accessed at: http:// epublications.uef.fi/pub/urn_isbn_978-952-61-0389-1/urn_isb n_978-952-61-0389-1.pdf.

[11] E. Lehtinen, K. Hakkarainen, L. Lipponen, M. Rahikainen, and H. Muukkonen, "Computer supported collaborative learning: A review", accessed at: http://www.comlab.hut.fi/opetus/205 /etatehtava1.pdf.

[12] T. Judd, G. Kennedy, and S. Cropper, "Using wikis for collaborative learning: Assessing collaboration through contribution." Australasian J. Educational Technology, vol. 26, No. 3, pp. 341-354, 2010.

[13] L. Lipponen, "The challenges for computer supported collaborative learning in elementary and secondary level: Finnish perspectives," in Proceedings of the Computer Support for Collaborative Learning (CSCL) 1999 Conference, C.M. Hoadley, J. Roschelle, Eds., Stanford University, Palo Alto, CA, December 12-15, 1999, International Society of the Learning Sciences.

[14] N. Akella, "The real deal on collaborative learning," Education, vol. 2, No. 3, pp. 23-29, 2012, doi: 10.5923/j.edu.20120203.01.

[15] D. Sporea and A. Sporea, "Europe of Innovative Science and Mathematics Education," Romanian Rep. Phys., vol. 66, No. 2, pp. 539-561, 2014. 
[16] N. Saab, W.R. Joolingen, and B.H.A.M. van Hout-Wolters, "Communication in collaborative discovery learning." British J. Educational Psychology, vol. 75, No. 4, pp. 603-621, 2005.

[17] H. Salovaara, "An exploration of students' strategy use in inquiry-based computer-supported collaborative learning." J. Computer Assisted Learning, vol. 21, No.1, pp. 39-52, 2005.

[18] K-E. Chang, Y-T. Sung, and C-L. Lee. "Web-based collaborative inquiry learning," J. computer assisted learning, vol. 19, No. 1, pp. 56-69, 2003.

[19] phpBB, https://www.phpbb.com/.
[20] Raphael Javascript Library, available at: http://raphaeljs.com/.

[21] HighCharts Javascript Interactive Charts, available at: http://www.highcharts.com/.

[22] The Fibonacci Project Presentation Booklet, available at: http://www.mines-stetienne.fr/sites/default/files/Fibonacci\%20 booklet $\% 20-\% 20$ web $\% 20$ version.pdf.

[23] AWSTATS, available at: http://awstats.sourceforge.net/. 